\title{
Brief hypnotherapeutic-behavioral intervention for functional abdominal pain and irritable bowel syndrome in childhood: a randomized controlled trial
}

\author{
Marco Daniel Gulewitsch • Judith Müller • \\ Martin Hautzinger • Angelika Anita Schlarb
}

Received: 11 February 2013 /Revised: 5 March 2013 /Accepted: 15 March 2013 /Published online: 9 April 2013

(C) Springer-Verlag Berlin Heidelberg 2013

\begin{abstract}
Functional abdominal pain and irritable bowel syndrome are two prevalent disorders in childhood which are associated with recurrent or chronic abdominal pain, disabilities in daily functioning, and reduced quality of life. This study aimed to evaluate a brief hypnotherapeuticbehavioral intervention program in a prospective randomized controlled design. Thirty-eight children, 6 to 12 years of age, and their parents were randomly assigned to a standardized hypnotherapeutic-behavioral treatment $(n=20)$ or to a waiting list condition $(n=18)$. Both groups were reassessed 3 months after beginning. Primary outcome variables were child-completed pain measures and pain-related disability. Secondary outcome variables were parent-completed measures of their children's pain and pain-related disability. Health-related quality of life from both perspectives also served as a secondary outcome. In the treatment group, 11 of 20 children $(55.0 \%)$ showed clinical remission (>80\% improvement), whereas only one child (5.6\%) in the waiting list condition was classified as responder. Children in the treatment group reported a significantly greater reduction of pain scores and pain-related disability than children of the waiting list condition. Parental ratings also showed a greater reduction of children's abdominal pain and pain-related disability. Health-related quality of life did not increase significantly. Conclusions: Hypnotherapeutic and behavioral interventions are effective in treating children with long-standing AP. Treatment success of this brief program
\end{abstract}

M. D. Gulewitsch $(\triangle) \cdot J$. Müller $\cdot$ M. Hautzinger $\cdot$ A. A. Schlarb Department of Psychology, Clinical Psychology and

Psychotherapy, University of Tübingen, Schleichstraße 4, 72076 Tübingen, Germany

e-mail: marco-daniel.gulewitsch@uni-tuebingen.de should be further evaluated against active interventions with a longer follow-up.

Keywords Functional abdominal pain · Irritable bowel syndrome $\cdot$ Children $\cdot$ Hypnotherapy $\cdot$ Randomizedcontrolled trial

\section{Introduction}

Recurrent or chronic abdominal pain (AP) is the most prevalent pain syndrome in childhood [15, 42, 45]. Because of the predominant absence of organic diseases [1,54], the recurring occurrence of AP is mostly classified as a functional gastrointestinal disorder (FGID) [39]. Functional abdominal pain (FAP) and irritable bowel syndrome (IBS) are the most frequent FGIDs in childhood [10,23] and are characterized by recurrent or continuous AP for at least 2 months [39]. IBS is additionally accompanied by changes in defecation (diarrhea and/or constipation) and/or relief of symptoms after defecation [39]. In the past, many studies did not use coherent criteria and did not distinguish between different symptom patterns such as FAP or IBS. This contributed to inconsistent prevalence rates in the range between 1 and $19 \%$ [7].

A considerable portion of visits in doctors' offices is caused by cases of AP of undetermined origin [29, 44]. Frequent AP is associated with substantial disabilities in quality of life and daily functioning [59], particularly in attending school $[29,38]$. A part of children with AP is at risk of symptom persistence till adulthood [5, 21, 24, 53]. Children with AP are found to score higher in questionnaires assessing psychopathological symptoms especially internalizing disturbances such as anxiety and other somatic 
complaints $[14,17,52]$. They also feature a high rate of psychiatric disorders such as anxiety disorders and depression $[4,36]$. Beyond psychological symptoms, a few studies report abnormalities in the function of the gut in terms of a heightened sensitivity of the gut [12] and modified gut motility [46].

Whereas dietary and pharmacological interventions are lacking in high quality evidence $[26,28]$, cognitive-behavioral interventions seem to be effective [27, 35]. Derived from good evidence in treating adults with long-standing IBS with hypnotherapy (HT) $[16,18,58]$, this might also be a promising approach in handling FAP and IBS in childhood [47-49]. The most comprehensive study in HT treatment of FAP and IBS in children and adolescents ( $8-18$ years) by a Dutch workgroup [48, 49] could demonstrate that HT was highly superior to standard medical care, even in a longterm follow-up. A study in the United States was able to show that self-administered audio-recorded HT for children and adolescents with FAP (6-15 years) was superior to a waiting list condition [47]. The employment of standardized psychotherapeutic interventions in childhood FGIDs is not common in Germany [20,44]. Therefore, we conducted a brief intervention program based on hypnotherapeutic and behavioral methods. With this concept, we focused on children aged 6 to 12. Preliminary results showed encouraging effects regarding pain characteristics and daily functioning [22]. The current study aimed on evaluating this intervention program in a prospective randomized controlled design, comparing a treatment group (TG) with a wait-list control group (WCG) three months after beginning.

\section{Materials and methods}

Study participants

Children had to be between 6 and 12 years of age. Inclusion criteria for the study were based on the Rome III definition of FAP and IBS. For participation, children had to feature recurrent or continuous AP for at least 2 months occurring at least once a week. In case of IBS, AP had to be associated additionally with two or more of the following at least $25 \%$ of the time: (1) improved with defecation, (2) onset associated with a change in frequency of stool, (3) onset associated with a change in form (appearance) of stool. A confirmation about the absence of organic diseases had been collected from the attending pediatrician or gastroenterologist. Exclusion criteria for the study were (1) ongoing specific treatment by another health care specialist (physician or psychotherapist) and (2) fulfilled criteria for functional dyspepsia or abdominal migraine.

Participant families were recruited from public announcements in local newspapers and at pediatricians' offices. The intervention was conducted at a university psychotherapeutic outpatient clinic. Fifty-four interested families were screened for eligibility, and 38 families (70.4\%) finally entered the trial. Reasons for exclusion of participants were nonfulfillment of diagnostic criteria $(n=8)$ and refusal of participation $(n=7)$. One family was excluded due to very bad German language skills. Remaining 38 participant families were randomly assigned following simple randomization procedures (computerized random number generator) to TG $(n=20)$ or WCG $(n=18)$. Details on recruiting are illustrated in Fig. 1.

All families gave informed consent to participate in the study. The study had been approved by the ethics committee of the University Hospital Tübingen.

\section{Treatment}

The treatment program $[22,43]$ consisted of four group sessions which split up in two children sessions and two parent sessions in a weekly sequence. Group size was between four and seven families. The treatment program was strictly standardized by a manual, and participants also received written information. Each treatment session lasted $90 \mathrm{~min}$ and was conducted by trained psychologists. The two sessions for the children addressed their abilities for self-instruction, relaxation, imagination, and provided information about the link between stress and AP. Both sessions included standardized hypnotherapeutic trances which aimed at increased wellbeing, the ability of being brave, and the ability of managing the pain (closing the "pain gate"). Children were instructed to practice these trances, recorded on a $\mathrm{CD}$, at home for 4 weeks at least five times a week (each 15-20 min). The two sessions for the parents comprised of information about FGIDs and their link to anxiety and stress, the individual identification of triggers, and information about positive educational strategies respective operant learning mechanisms in terms of secondary gain.

\section{Measures}

Children and their parents in the TG filled out questionnaires before the start of the treatment. The treatment lasted for 4 weeks. Two months after ending the treatment (3 months after the start), the participants were reassessed. Participant families in the WCG filled out questionnaires before the start of the waiting time and 3 months after the start of the waiting time.

Baseline measures

The Child Behavior Checklist 4/18 (CBCL) [6] consists of 113 behavior and emotional problems during the previous 6 months which were rated by the parents as being not true, sometimes or somewhat true, or very or often true. The 


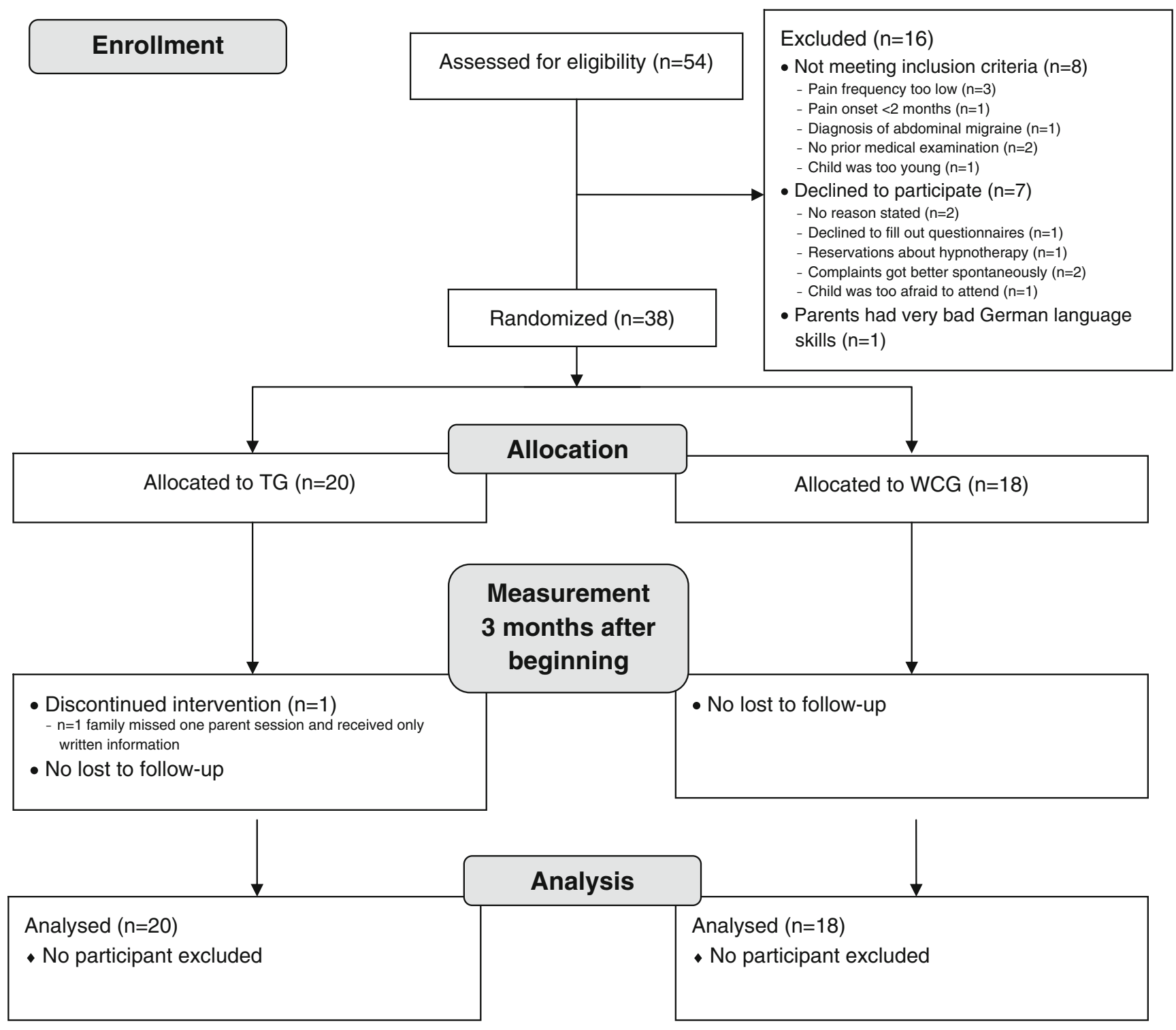

Fig. 1 Flow diagram of study participants

CBCL is a widely used and well validated screening instrument for children's psychopathology [32]. We employed the three major scores of internalizing difficulties, externalizing difficulties, and total difficulties. The CBCL was only used for baseline comparisons of children's psychopathology and was therefore not included in the follow-up measurement.

Primary outcome measures

Because of the risk of possible underreporting, measurement of pain should be obtained directly from the children and serve as primary outcome variable [2]. Participating children kept a pain diary for 2 weeks at both measurement points. The pain diary recorded the number of days with AP, the mean intensity, and the mean duration of pain episodes. It was also assessed whether the child missed school because of AP. Pain intensity was rated on a numeric rating scale from 1 to 10 ("very little pain" to "the most pain possible"). The duration of AP was scored as: $0=$ no pain, $1=$ a few minutes, $2=$ about half an hour, $3=$ about an hour, $4=$ between 1 and 2 h, $5=3$ or $4 \mathrm{~h}, 7=$ most of the day and $8=$ all day (it never completely stops). The classification of pain duration was taken over from the widely used abdominal pain index (API) [55].

The Rome expert panel recommended that in trials for FGIDs, one primary outcome measure should be the percentage of subjects meeting a predetermined clinical outcome [30]. For this purpose, we calculated an additive index of AP based on the three pain ratings of the pain diary (days with pain + pain duration + pain intensity). Because of the different scaling of the three pain ratings, the index of AP is calculated from standardized $z$ values. This procedure considers various symptom patterns (e.g., scarce but 
intensive AP or frequent but weak AP) and is similar to the API [55]. In many studies, a $50 \%$ symptom improvement is considered to be a reasonable definition of a treatment responder [8], but we applied a more conservative categorization, which was also used in a previous trial addressing childhood FGIDs [48, 49]. Participating children with $>80 \%$ improvement of the index were considered as responders with a clinical remission. An improvement between 30-80 \% was defined as "significant improvement." The treatment was considered to be unsuccessful if the scores improved only $<30 \%$ or got worse.

The self-reported pain-related disability was assessed by the one-dimensional pediatric-pain disability index (P-PDI) [25]. The P-PDI assesses pain-related impairment in 12 daily activities, with each ranging from $1=$ never to $5=$ always. The self-report featured good internal consistency ( $\alpha=.87)$ [25]. In our sample, we found an internal consistency of $\alpha=.85$.

\section{Secondary outcome measures}

Parents were asked to rate their children's AP with the parental form of the five-item abdominal pain index (API) [55]. The API assessed the frequency of AP within the last 2 weeks on a 6-point scale from "not at all" to "every day." The daily frequency was also rated on a 6-point scale from "none" to "constant during the day." Usual duration of a pain episode was rated on a 9-point scale from "none" to "all day." The usual intensity of a pain episode and the maximum intensity were scored using two 10-point scales ranging from "no pain" to "the most pain possible." Because of the different answer formats of the five pain ratings, the variables were $z$-standardized and added up to provide a balanced index of AP. Previous studies [55] have shown adequate internal consistency of the API ( $\alpha$ $=.80-93)$, which could be confirmed in our sample $(\alpha=.87)$.

As a secondary outcome, the P-PDI was also administered to the parents. The parent-completed P-PDI is parallel to the previously described children version. In our sample, the internal consistency of the parental report was $\alpha=.84$.

Health-related quality of life (HRQoL) is recommended as secondary outcome in trials for the treatment of FGIDs [30]. It was assessed in children using the revised German KINDL questionnaire [40], which exhibits three age versions. The KINDL is a well validated measure of HRQoL [40, 41]. We applied the KINDL-Kiddy (age 4-7 years) and the KINDL-Kid (8-12 years) with both parental and self-appraisals. The KINDL-Kid consists of 24 items and the KINDL-Kiddy of 22 items, each ranging from $1=$ never to $5=$ always. The total score ranges from 0 (lowest HRQoL) to 100 (highest HRQoL).

\section{Statistics}

Baseline differences between the two groups were examined using $\chi^{2}$ tests for frequencies and $t$ tests for data based on means. When normal distribution could not be assumed, Mann-Whitney U test was used for comparisons between means. Mann-Whitney U test was also used for comparing ordinal scaled data. Changes from pre to post were calculated with univariate repeated-measures ANOVAs. Dependent variables yielding univariate significance were included in two repeated-measures MANOVAs (one for children's and one for parent's perspective) to control for interactions among the dependent variables and multiple testing. In case of superiority of one treatment group, we expected significant time $\times$ group interactions in (M)ANOVAs. (M)ANOVA effect sizes are reported as $\eta^{2}$ (small effect $\eta^{2}=0.01$, medium effect $\eta^{2}=0.06$, strong effect $\left.\eta^{2}=0.14\right)$. All tests were two-tailed, and the significance level was set at $p<0.05$. Based on our previous results [22], we expected medium effect sizes regarding the time $\times$ group interactions. To ensure medium effects with a power of .80 , at least 34 children (17 per group) had to be included in the trial. Statistical analyses were performed using SPSS (version 20).

\section{Results}

A total of 38 children and their parents entered the trial. The sample consisted of 24 girls (63.2\%) and 14 boys (36.8\%) with a mean age of $\mathrm{M}=9.37$ years $(\mathrm{SD}=1.72)$. An amount of 29 children, $76.3 \%$ of the sample, fulfilled criteria for FAP, and 9 children were diagnosed to have IBS $(23.7 \%)$. On average, the onset of complaints was 34.6 months ago ( $\mathrm{SD}=40.41 ; 2.9$ years).

As reported in Table 1, there were no differences between the TG and WCG after randomization. TG and WCG did not differ with regard to demographic characteristics, pain characteristics, or behavioral and emotional problems (CBCL).

\section{Primary outcomes}

Children in the TG reported a greater reduction of days with AP compared to children in the WCG, which is supported by a significant time $\times$ group interaction $(\mathrm{F}=4.25, p=.046$, $\left.\eta^{2}=.106\right)$. At follow-up, children in the TG reported 1.8 pain days during the diary period of 2 weeks (decrease of 6.1 days) whereas children in the WCG reported 6.2 days (decrease of 3.3 days). Children's reports of mean intensity of pain episodes decreased significantly stronger in the TG than in the WCG group $\left(\mathrm{F}=8.27, p=.007, \eta^{2}=.187\right)$ from 4.2 points to 1.6 points, respectively, 5.0 points to 4.5 points (scaled from 1 to 10). Mean duration of pain episodes also shortened significantly more in the TG group $(\mathrm{F}=6.57$, $\left.p=.015, \eta^{2}=.154\right)$. As missing school was reported seldom at baseline and at follow-up, no sound calculation could be carried out. Pain-related disability as reported 
Table 1 Baseline characteristics of participants by treatment group

\begin{tabular}{|c|c|c|c|c|}
\hline & $\begin{array}{l}\text { TG } \\
n=20\end{array}$ & $\begin{array}{l}\text { WCG } \\
n=18\end{array}$ & $\mathrm{t} / \chi^{2} / \mathrm{U}$ & $\mathrm{p}$ \\
\hline Mean age (SD) & $9.11(1.65)$ & $9.66(1.79)$ & $\mathrm{t}=-.989$ & $p=.329$ \\
\hline Gender (female to male) & $\begin{array}{l}11 \text { to } 9 \\
(55.0 \text { to } 45.0 \%)\end{array}$ & $\begin{array}{l}13 \text { to } 5 \\
(72.2 \text { to } 27.8 \%)\end{array}$ & $\chi^{2}=1.21$ & $p=.272$ \\
\hline Duration of AP in months (SD) & $30.45(41.04)$ & $39.22(40.36)$ & $\mathrm{t}=-.663$ & $p=.511$ \\
\hline Consultations of a physician in the last 3 months (SD) & $1.06(0.90)$ & $1.97(2.02)$ & $\mathrm{U}=121.50$ & $p=.303$ \\
\hline \multicolumn{5}{|l|}{ Diagnosis according to Rome III } \\
\hline FAP $(\%)$ & 14 of $20(70.0 \%)$ & 15 of $18(83.3 \%)$ & $\chi^{2}=.932$ & $p=.334$ \\
\hline IBS $(\%)$ & 6 of $20(30.0 \%)$ & 3 of $18(16.7 \%)$ & & \\
\hline \multicolumn{5}{|l|}{ Missed school days in the last 3 months } \\
\hline Never & 10 of $20(50.0 \%)$ & 7 of $18(38.9 \%)$ & $\mathrm{U}=143.00$ & $p=.290$ \\
\hline 1 day & 6 of $20(30.0 \%)$ & 4 of $18(22.2 \%)$ & & \\
\hline 2 to 7 days & 4 of $20(20.0 \%)$ & 5 of $18(27.8 \%)$ & & \\
\hline More than a week & 0 of $20(0 \%)$ & 2 of $18(11.1 \%)$ & & \\
\hline \multicolumn{5}{|l|}{ Pain characteristics (parental rating) } \\
\hline Common intensity of pain episodes in the last 3 months $[1-10]$ (SD) & $4.08(1.34)$ & $4.18(1.35)$ & $\mathrm{t}=-.229$ & $p=.820$ \\
\hline Maximum intensity of pain episodes in the last 3 months [1-10] (SD] & $5.60(1.82)$ & $4.88(1.73)$ & $\mathrm{t}=1.22$ & $p=.229$ \\
\hline Common duration of pain episodes in the last 3 months [score 1-8] (SD) & $3.45(2.28)$ & $3.39(2.17)$ & $\mathrm{U}=176.50$ & $p=.919$ \\
\hline API score of the last 2 weeks, $z$ values (SD) & $1.56(2.90)$ & $1.85(2.98)$ & $\mathrm{t}=-.305$ & $p=.762$ \\
\hline \multicolumn{5}{|l|}{ Pain characteristics (child's rating) } \\
\hline Number of recorded days with pain in diary [0-14] (SD) & $7.90(4.82)$ & $9.50(4.08)$ & $\mathrm{t}=-1.10$ & $p=.280$ \\
\hline Mean intensity of pain episodes in diary [1-10] (SD) & $4.18(1.19)$ & $5.03(1.65)$ & $\mathrm{t}=-1.83$ & $p=.075$ \\
\hline Mean duration score of pain episodes in diary [1-8] (SD) & $3.40(2.35)$ & $3.50(2.36)$ & $\mathrm{t}=-.131$ & $p=.897$ \\
\hline \multicolumn{5}{|l|}{ Emotional/behavioral problems (parental rating) } \\
\hline CBCL internalizing T-score (SD) & $67.00(7.70)$ & $67.28(7.86)$ & $\mathrm{t}=-.110$ & $p=.913$ \\
\hline CBCL externalizing T-score (SD) & $55.75(7.49)$ & $56.50(6.96)$ & $\mathrm{t}=-.319$ & $p=.752$ \\
\hline CBCL total T-score (SD) & $62.50(7.83)$ & $62.61(7.80)$ & $\mathrm{t}=-.044$ & $p=.965$ \\
\hline
\end{tabular}

$M$ mean, $S D$ standard deviation, $T G$ therapy group, $W C G$ waitlist-control group, $A P$ abdominal pain, $F A P$ functional abdominal pain, $I B S$ irritable bowel syndrome, $A P I$ abdominal pain index, $C B C L$ Child Behavior Checklist 4/18

by the children improved from baseline to postmeasurement in the TG; whereas, it remained stable in the WCG $\left(\mathrm{F}=6.73, p=.014, \eta^{2}=.161\right)$.

The responder analysis was based on an additive index of AP derived from the children's pain diaries. In the TG 11 of 20 children $(55.0 \%)$ showed clinical remission $(>80 \%$ improvement), whereas only one child $(5.6 \%)$ in the WCG was classified as responder $(p=.002)$. Five children $(25.0 \%)$ in the TG and five children in the WCG $(27.8 \%)$ showed a significant symptom improvement between 30 $80 \%$. Four children of the TG $(20.0 \%)$ and 12 children $(66.7 \%)$ of the WCG did not improve or got worse.

Secondary outcomes

Parent's reports of AP symptoms were measured using the API. From baseline to follow-up, univariate analysis revealed a significantly stronger reduction of symptoms in the TG $\left(\mathrm{F}=7.57, p=.009, \eta^{2}=.174\right)$. Pain-related disability as reported by the parents also improved significantly more in the TG $\left(\mathrm{F}=7.27, p=.011, \eta^{2}=.168\right)$.

Self-reported HRQoL improved in the TG and not in the WCG at follow-up, but the interaction between group and time factor failed to reach significance $(\mathrm{F}=2.56, p=.120)$. Parental rating of HRQoL improved in both conditions and showed no differential effect between the two groups $(\mathrm{F}=0.18, p=.678)$.

Multivariate analysis for child-completed and parentcompleted measures

An additional repeated-measures MANOVA which included the three child-completed pain parameters and the pain-related disability demonstrated that all four parameters still reached significance regarding the time $\times$ group interaction, indicating a superiority of the TG from the children's perspective. Detailed values can be obtained from Table 2 . 
A second multivariate analysis for the parent's perspective included also the variables which were found to be significant in univariate analysis. As shown in Table 2, both AP symptoms und pain-related disability still reached significance regarding the time $\times$ group interaction in the MANOVA, indicating a superiority of TG from the parent's perspective in terms of AP symptoms and disability.

\section{Discussion}

The primary result of this study is that a brief hypnotherapeutic and behavioral intervention (TG) was able to reduce the pain frequency, pain duration, and pain intensity significantly compared to a waiting list control group. The superiority of the TG could be ascertained for children's and parent's reports of the symptoms. Additionally, we could demonstrate that children receiving the treatment showed a significant stronger improvement of pain-related disability compared the children who were waiting on the treatment to start. Interestingly, the TG showed no superiority regarding HRQoL from children's or parent's perspective. At follow-up, the TG featured a high rate of treatment responders $(55 \%)$, whereas only one child of the WCG improved to this extent. This result corresponds to the finding by Vlieger and colleagues [48], who found a rate of $59 \%$ treatment response $(>80 \%$ improvement) after 3 months in a group of children and adolescents with FAP or IBS receiving HT. Van Tilburg and colleagues reported in their HT trial a treatment response rate $(\geq 50 \%$ improvement) of $63 \%$ after 1 month and $63 \%$ after six months. On the one hand, the high rate of treatment responders is remarkable since the majority of children suffered from long-standing AP. On the other hand, this is in line with previous research in adults, which has shown that HT is highly effective in the treatment of adult patients with severe IBS, who did not benefit from other treatments [18].

Even though most children with frequent AP are lacking explanatory organic diseases [1] and a substantial proportion of children exhibits psychological problems $[14,17,52]$, it cannot be concluded that frequent nonorganic AP is caused by psychological factors [11]. FGIDs are thought to be strongly linked to a disordered brain-gut interaction [13]: Stress and unpleasant emotional states lead to hypervigilance and hence to an increase of arousal of the autonomous nervous system and the endocrine system, which may contribute to a heightened sensitivity of the gut and modified gut motility [13, 31]. Additionally, persistent experiences of pain may have an adverse effect on psychological symptoms. The efficiency of psychotherapeutic treatments [27] is probably caused by their modification of this interplay of psychological and physiologic processes (e.g., reduction of arousal and change of coping behavior).

HT aims to induce a hypnotic state ("trance"), which can be achieved by deep relaxation or imagination and is followed by direct and indirect suggestions. It is assumed that persons in this state have a better ability to assimilate new concepts about their problem [19], but the mechanisms by which HT has an influence on FGIDs are not well known. Till now, there is evidence (mainly from adults' studies) that HT reduces autonomic reactivity [34], influences gut motility [57], and normalizes visceral sensitivity [33]. In contrast, the only intervention study which examined a sample of children and adolescents with FAP or IBS by physiological measures concluded that the symptom reduction following HT could not be explained by relief of visceral (rectal) sensitivity [50].

The behavioral elements of our intervention addressed the parents' direct behavioral response on their children's somatic complaints and the explanation of a biopsychosocial model. Based on operant conditioning, parental reaction has a notable influence on childhood AP [51, 56]. Therefore, parents might contribute to a maladaptive role by showing positive consequences to it. Other studies highlight the importance of parental acceptance of a biopsychosocial model for the explanation of the child's symptoms which was associated with long-term symptom recovery [9, 37]. A three-session cognitive-behavioral intervention study by Levy and coauthors [35] aimed mainly at modifying the families' response on illness behavior of the child and could demonstrate a long-lasting reduction of parentreported AP in a large sample. Beyond this, the empowerment of parents to take an active role in their child's treatment might help to reduce helplessness and contribute crucially to treatment success. However, it must be pointed out that our combination of HT and behavioral interventions did not allow drawing conclusions of which components were effective and which were not.

We did not find an effect regarding HRQoL. This may be due to the already high HRQoL values at baseline. Both groups exhibited baseline values between 69 and 70 points from both perspectives which is only one standard deviation or less below the means of population [3]. As reported by the children, only the TG improved between the two time points but failed to reach significance. Parents in both conditions reported a similar increase of HRQoL (6.6 or 8.4 points). A condition-specific measure for assessing HRQoL might be more suitable.

The treatment gained a high compliance. No family dropped out during the intervention, and all families completed their follow-up measures. Previous results showed a high acceptance of the treatment program [22]. No adverse side effects were mentioned or observed. 
Table 2 Means and multivariate comparison of primary outcome measures for treatment group and wait-list control group

\begin{tabular}{|c|c|c|c|c|c|c|}
\hline & \multirow[t]{2}{*}{ Group } & \multirow{2}{*}{$\begin{array}{l}\text { Pre } \\
\text { M (SD) }\end{array}$} & \multirow{2}{*}{$\begin{array}{l}\text { Post } \\
\text { M (SD) }\end{array}$} & \multicolumn{3}{|c|}{ Time $\times$ group interaction } \\
\hline & & & & $\mathrm{F}$ & $\mathrm{p}$ & $\eta^{2}$ \\
\hline \multicolumn{7}{|l|}{ Child's rating } \\
\hline \multirow[t]{2}{*}{ Number of recorded days with pain in diary [0-14] } & TG & $7.90(4.82)$ & $1.80(2.95)$ & 4.83 & .035 & .121 \\
\hline & WCG & $9.50(4.08)$ & $6.17(4.55)$ & & & \\
\hline \multirow[t]{2}{*}{ Mean intensity of pain episodes $[1-10]$} & TG & $4.18(1.19)$ & $1.60(2.45)$ & 8.80 & .005 & .201 \\
\hline & WCG & $5.03(1.65)$ & $4.46(2.33)$ & & & \\
\hline \multirow[t]{2}{*}{ Mean duration score of pain episodes $[1-8]$} & TG & $3.40(2.35)$ & $1.20(1.47)$ & 6.64 & .014 & .159 \\
\hline & WCG & $3.50(2.36)$ & $3.50(2.53)$ & & & \\
\hline \multirow[t]{2}{*}{ Pain-related disability score (P-PDI) [12-60] } & TG & $28.24(8.10)$ & $18.53(9.44)$ & 6.73 & .014 & .161 \\
\hline & WCG & $28.17(10.51)$ & $27.67(7.07)$ & & & \\
\hline \multicolumn{7}{|l|}{ Parental rating } \\
\hline \multirow[t]{2}{*}{ API score of the last 2 weeks, $z$ values } & TG & $1.56(2.90)$ & $-3.91(3.56)$ & 7.57 & .009 & .174 \\
\hline & WCG & $1.85(2.98)$ & $0.63(4.57)$ & & & \\
\hline \multirow[t]{2}{*}{ Pain-related disability score (P-PDI) [12-60] } & TG & $25.01(6.62)$ & $16.13(5.23)$ & 7.27 & .011 & .168 \\
\hline & WCG & $24.89(8.09)$ & $22.44(6.33)$ & & & \\
\hline
\end{tabular}

$M$ mean, $S D$ standard deviation, $T G$ therapy group, $W C G$ waitlist-control group, $P-P D I$ pediatric pain disability index, $H R Q o L$ health-related quality of life, $A P I$ abdominal pain index

A great strength of our concept is that the treatment is very short, and that it is administered in small groups. This makes it easy and cheap to implement. Although children with AP are affected by this condition from months to years [53], there is growing evidence of the efficiency of very brief psychosocial interventions in treating AP [35, 47, 48].

This study delivers preliminary evidence that our standardized treatment is effective among children with longstanding FAP or IBS, but there are also several limitations: First, the control group was a wait-list control group and did not receive an active treatment. The use of the wait-list control group provides only evidence that the outcome of the intervention (TG) is better than the natural course of AP (WCG). Beyond this, a wait-list design does not control for general therapeutic factors such as attention or expectation of a future symptom improvement. The intervention should be further evaluated against active interventions (e.g., children's relaxation training or parental counseling). Second, the wait-list design did not allow a more extended controlled follow-up, and the long-term effect of the intervention is unknown. Third, our sample sizes were too small for analyses according to gender, age group, or Rome III diagnosis.

Further studies should consider comparing this intervention to an active control group. Dismantling the components of the treatment could additionally clear up which components are effective and which are not. Measurement should be supplemented by a condition-specific assessment of HRQoL, the assessment of cognitive variables such as the children's ability to cope with symptoms and by follow-up assessment of psychopathology. Ambulatory recording of psychophysiological variables (e.g., heart rate variability) before and after treatment could contribute to figure out potential mechanisms of action.

Acknowledgments The authors thank Ms. Julia Sarah Schauer and Ms. Andrea Bauer for their assistance in participant enrollment, data collection, and carrying out the treatment.

The authors declare that they have no conflict of interest.

\section{References}

1. Alfven G (2003) One hundred cases of recurrent abdominal pain in children: diagnostic procedures and criteria for a psychosomatic diagnosis. Acta Paediatr 92(1):43-49

2. Ball TM, Weydert JA (2003) Methodological challenges to treatment trials for recurrent abdominal pain in children. Arch Pediatr Adolesc Med 157(11):1121-1127

3. Bullinger M, Brutt AL, Erhart M, Ravens-Sieberer U (2008) Psychometric properties of the KINDL-R questionnaire: results of the BELLA study. Eur Child Adolesc Psychiatry 17(Suppl 1):125-132

4. Campo JV, Bridge J, Ehmann M, Altman S, Lucas A, Birmaher B, Di Lorenzo C, Iyengar S, Brent DA (2004) Recurrent abdominal pain, anxiety, and depression in primary care. Pediatrics 113(4):817-824

5. Campo JV, Di Lorenzo C, Chiappetta L, Bridge J, Colborn DK, Gartner JC Jr, Gaffney P, Kocoshis S, Brent D (2001) Adult outcomes of pediatric recurrent abdominal pain: do they just grow out of it? Pediatrics 108(1):E1

6. Arbeitsgruppe deutsche Child Behavior Checklist (1998) Elternfragebogen über das Verhalten von Kindern und Jugendlichen: Deutsche Bearbeitung der Child Behavior Checklist (CBCL 4-18). Einführung und Anleitung zur Handauswertung (2. 
Aufl.). Arbeitsgruppe Kinder-, Jugend- und Familiendiagnostik (KJFD), Köln

7. Chitkara DK, Rawat DJ, Talley NJ (2005) The epidemiology of childhood recurrent abdominal pain in Western countries: a systematic review. Am J Gastroenterol 100(8):1868-1875

8. Corazziari E, Bytzer P, Delvaux M, Holtmann G, Malagelada JR, Morris J, Muller-Lissner S, Spiller RC, Tack J, Whorwell PJ (2003) Clinical trial guidelines for pharmacological treatment of irritable bowel syndrome. Aliment Pharmacol Ther 18(6):569-580

9. Crushell E, Rowland M, Doherty M, Gormally S, Harty S, Bourke B, Drumm B (2003) Importance of parental conceptual model of illness in severe recurrent abdominal pain. Pediatrics $112(6 \mathrm{Pt}$ 1):1368-1372

10. Devanarayana NM, Mettananda S, Liyanarachchi C, Nanayakkara N, Mendis N, Perera N, Rajindrajith S (2011) Abdominal painpredominant functional gastrointestinal diseases in children and adolescents: prevalence, symptomatology, and association with emotional stress. J Pediatr Gastroenterol Nutr 53(6):659-665

11. Di Lorenzo C (2005) Abdominal pain: is it in the gut or in the head? J Pediatr Gastroenterol Nutr 41:S44-S46

12. Di Lorenzo C, Youssef NN, Sigurdsson L, Scharff L, Griffiths J, Wald A (2001) Visceral hyperalgesia in children with functional abdominal pain. J Pediatr 139(6):838-843

13. Drossman DA, Camilleri M, Mayer EA, Whitehead WE (2002) AGA technical review on irritable bowel syndrome. Gastroenterology 123(6):2108-2131

14. Dufton LM, Dunn MJ, Compas BE (2009) Anxiety and somatic complaints in children with recurrent abdominal pain and anxiety disorders. J Pediatr Psychol 34(2):176-186

15. Ellert U, Neuhauser H, Roth-Isigkeit A (2007) Schmerzen bei Kindern und Jugendlichen in Deutschland: Pravalenz und Inanspruchnahme medizinischer Leistungen. Ergebnisse des Kinder- und Jugendgesundheitssurveys (KiGGS). Bundesgesundheitsbl Gesundheitsforsch Gesundheitsschutz 50(5-6):711-717

16. Forbes A, MacAuley S, Chiotakakou-Faliakou E (2000) Hypnotherapy and therapeutic audiotape: effective in previously unsuccessfully treated irritable bowel syndrome? Int J Color Dis 15(56):328-334

17. Galli F, D'Antuono G, Tarantino S, Viviano F, Borrelli O, Chirumbolo A, Cucchiara S, Guidetti V (2007) Headache and recurrent abdominal pain: a controlled study by the means of the Child Behavior Checklist (CBCL). Cephalalgia 27(3):211-219

18. Gonsalkorale WM, Miller V, Afzal A, Whorwell PJ (2003) Long term benefits of hypnotherapy for irritable bowel syndrome. Gut 52(11):1623-1629

19. Gonsalkorale WM, Whorwell PJ (2005) Hypnotherapy in the treatment of irritable bowel syndrome. Eur J Gastroenterol Hepatol 17(1):15-20

20. Gross M, Warschburger P (2012) Evaluation of a cognitive-behavioral pain management program for children with chronic abdominal pain: a randomized controlled study. Int J Behav Med. doi:10.1007/s12529-012-9228-3

21. Gulewitsch MD, Enck P, Hautzinger M, Schlarb AA (2011) Irritable bowel syndrome symptoms among German students: prevalence, characteristics, and associations to somatic complaints, sleep, quality of life, and childhood abdominal pain. Eur J Gastroenterol Hepatol 23(4):311-316

22. Gulewitsch MD, Schauer JS, Hautzinger M, Schlarb AA (2012) Therapy of functional abdominal pain in childhood. Concept, acceptance, and preliminary results of a short hypnotherapeuticbehavioral intervention. Schmerz 26(2):160-167

23. Helgeland H, Flagstad G, Grotta J, Vandvik PO, Kristensen H, Markestad T (2009) Diagnosing pediatric functional abdominal pain in children (4-15 years old) according to the Rome III criteria: results from a Norwegian prospective study. J Pediatr Gastroenterol Nutr 49(3):309-315

24. Hotopf M, Carr S, Mayou R, Wadsworth M, Wessely S (1998) Why do children have chronic abdominal pain, and what happens to them when they grow up? Population based cohort study. BMJ 316(7139):1196-1200

25. Hübner B, Hechler T, Dobe M, Damschen U, Kosfelder J, Denecke H, Schroeder S, Zernikow B (2009) Pain-related disability in adolescents suffering from chronic pain. Preliminary examination of the pediatric pain disability index (P-PDI). Schmerz 23(1):20-32

26. Huertas-Ceballos A, Logan S, Bennett C, Macarthur C (2008) Pharmacological interventions for recurrent abdominal pain (RAP) and irritable bowel syndrome (IBS) in childhood. Cochrane database of systematic reviews(1):CD003017. doi:10.1002/ 14651858.CD003017.pub2

27. Huertas-Ceballos A, Logan S, Bennett C, Macarthur C (2008) Psychosocial interventions for recurrent abdominal pain (RAP) and irritable bowel syndrome (IBS) in childhood. Cochrane database of systematic reviews(1):CD003014. doi:10.1002/ 14651858.CD003014.pub2

28. Huertas-Ceballos AA, Logan S, Bennett C, Macarthur C (2009) Dietary interventions for recurrent abdominal pain (RAP) and irritable bowel syndrome (IBS) in childhood. Cochrane database of systematic reviews(1):CD003019. doi:10.1002/ 14651858.CD003019.pub3

29. Hyams JS, Burke G, Davis PM, Rzepski B, Andrulonis PA (1996) Abdominal pain and irritable bowel syndrome in adolescents: a community-based study. J Pediatr 129(2):220-226

30. Irvine EJ, Whitehead WE, Chey WD, Matsueda K, Shaw M, Talley NJ, Veldhuyzen van Zanten SJ (2006) Design of treatment trials for functional gastrointestinal disorders. Gastroenterology 130(5):1538-1551

31. Jones MP, Dilley JB, Drossman D, Crowell MD (2006) Brain-gut connections in functional GI disorders: anatomic and physiologic relationships. Neurogastroenterol Motil 18(2):91-103

32. Klasen H, Woerner W, Wolke D, Meyer R, Overmeyer S, Kaschnitz W, Rothenberger A, Goodman R (2000) Comparing the German versions of the strengths and difficulties questionnaire (SDQ-Deu) and the child behavior checklist. Eur Child Adolesc Psychiatr 9(4):271-276

33. Lea R, Houghton LA, Calvert EL, Larder S, Gonsalkorale WM, Whelan V, Randles J, Cooper P, Cruickshanks P, Miller V, Whorwell PJ (2003) Gut-focused hypnotherapy normalizes disordered rectal sensitivity in patients with irritable bowel syndrome. Aliment Pharmacol Ther 17(5):635-642

34. Lee LH, Olness KN (1996) Effects of self-induced mental imagery on autonomic reactivity in children. J Dev Behav Pediatr 17(5):323-327

35. Levy RL, Langer SL, Walker LS, Romano JM, Christie DL, Youssef N, DuPen MM, Feld AD, Ballard SA, Welsh EM, Jeffery RW, Young M, Coffey MJ, Whitehead WE (2010) Cognitivebehavioral therapy for children with functional abdominal pain and their parents decreases pain and other symptoms. Am J Gastroenterol 105(4):946-956

36. Liakopoulou-Kairis M, Alifieraki T, Protagora D, Korpa T, Kondyli K, Dimosthenous E, Christopoulos G, Kovanis T (2002) Recurrent abdominal pain and headache. Eur Child Adolesc Psychiatry 11(3):115-122

37. Lindley KJ, Glaser D, Milla PJ (2005) Consumerism in healthcare can be detrimental to child health: lessons from children with functional abdominal pain. Arch Dis Child 90(4):335-337

38. Ramchandani PG, Fazel M, Stein A, Wiles N, Hotopf M (2007) The impact of recurrent abdominal pain: predictors of outcome in a large population cohort. Acta Paediatr 96(5):697-701 
39. Rasquin A, Di Lorenzo C, Forbes D, Guiraldes E, Hyams JS, Staiano A, Walker LS (2006) Childhood functional gastrointestinal disorders: child/adolescent. Gastroenterology 130(5):1527-1537

40. Ravens-Sieberer U, Bullinger M (1998) Assessing health-related quality of life in chronically ill children with the German KINDL: first psychometric and content analytical results. Qual Life Res 7(5):399-407

41. Ravens-Sieberer U, Ellert U, Erhart M (2007) Gesundheitsbezogene Lebensqualität von Kindern und Jugendlichen in Deutschland. Bundesgesundheitsbl Gesundheitsforsch Gesundheitsschutz 50(56):810-818

42. Roth-Isigkeit A, Thyen U, Raspe HH, Stöven H, Schmucker P (2004) Reports of pain among German children and adolescents: an epidemiological study. Acta Paediatr 93(2):258-263

43. Schlarb AA, Gulewitsch MD (in press) Manual "Sun in your belly". Kohlhammer, Stuttgart

44. Schlarb AA, Gulewitsch MD, Bock genannt Kasten I, Enck P, Hautzinger $M$ (2011) Recurrent abdominal pain in children and adolescents-a survey among pediatricians. Psychosoc Med 8: Doc02

45. Schwille IJ, Giel KE, Ellert U, Zipfel S, Enck P (2009) A community-based survey of abdominal pain prevalence, characteristics, and health care use among children. Clin Gastroenterol Hepatol 7(10):1062-1068

46. Van Ginkel R, Voskuijl WP, Benninga MA, Taminiau JA, Boeckxstaens GE (2001) Alterations in rectal sensitivity and motility in childhood irritable bowel syndrome. Gastroenterology 120(1):31-38

47. Van Tilburg MA, Chitkara DK, Palsson OS, Turner M, Blois-Martin N, Ulshen M, Whitehead WE (2009) Audio-recorded guided imagery treatment reduces functional abdominal pain in children: a pilot study. Pediatrics 124(5):e890-e897

48. Vlieger AM, Menko-Frankenhuis C, Wolfkamp SC, Tromp E, Benninga MA (2007) Hypnotherapy for children with functional abdominal pain or irritable bowel syndrome: a randomized controlled trial. Gastroenterology 133(5):1430-1436

49. Vlieger AM, Rutten JM, Govers AM, Frankenhuis C, Benninga MA (2012) Long-term follow-up of gut-directed hypnotherapy vs. standard care in children with functional abdominal pain or irritable bowel syndrome. Am J Gastroenterol 107(4):627-631

50. Vlieger AM, van den Berg MM, Menko-Frankenhuis C, Bongers ME, Tromp E, Benninga MA (2010) No change in rectal sensitivity after gut-directed hypnotherapy in children with functional abdominal pain or irritable bowel syndrome. Am J Gastroenterol 105(1):213-218

51. Walker LS, Claar RL, Garber J (2002) Social consequences of children's pain: when do they encourage symptom maintenance? J Pediatr Psychol 27(8):689-698

52. Walker LS, Greene JW (1989) Children with recurrent abdominal pain and their parents: more somatic complaints, anxiety, and depression than other patient families? J Pediatr Psychol 14(2):231-243

53. Walker LS, Guite JW, Duke M, Barnard JA, Greene JW (1998) Recurrent abdominal pain: a potential precursor of irritable bowel syndrome in adolescents and young adults. J Pediatr 132(6):1010 1015

54. Walker LS, Lipani TA, Greene JW, Caines K, Stutts J, Polk DB, Caplan A, Rasquin-Weber A (2004) Recurrent abdominal pain: symptom subtypes based on the Rome II Criteria for pediatric functional gastrointestinal disorders. J Pediatr Gastroenterol Nutr 38(2):187-191

55. Walker LS, Smith CA, Garber J, VanSlyke DA (1997) Development and validation of the pain response inventory for children. Psychol Assess 9(4):392-405

56. Walker LS, Williams SE, Smith CA, Garber J, Van Slyke DA, Lipani TA (2006) Parent attention versus distraction: impact on symptom complaints by children with and without chronic functional abdominal pain. Pain 122(1-2):43-52

57. Whorwell PJ, Houghton LA, Taylor EE, Maxton DG (1992) Physiological effects of emotion: assessment via hypnosis. Lancet 340(8811):69-72

58. Whorwell PJ, Prior A, Faragher EB (1984) Controlled trial of hypnotherapy in the treatment of severe refractory irritable-bowel syndrome. Lancet 2(8414):1232-1234

59. Youssef NN, Murphy TG, Langseder AL, Rosh JR (2006) Quality of life for children with functional abdominal pain: a comparison study of patients' and parents' perceptions. Pediatrics 117(1):54-59 